\title{
Fabrication of Alumina Ceramic Filters and Performance Tests for Aluminium Castings
}

\author{
A. DEMIR* \\ Sakarya University, Department of Metallurgical and Materials Engineering, Faculty of Technology, Sakarya, Turkey
}

\begin{abstract}
Alumina ceramic foam filters are developed for filtering impurities from aluminium and aluminium alloys while molten metal is entering to the mould. Cleaning liquid metal results in higher-quality castings, less scrap, and fewer inclusion defects. $\mathrm{Al}_{2} \mathrm{O}_{3}$ ceramic foam filter has been recently developed as a new type of molten metal filter to decrease casting flow in recent years. Foam filters can effectively remove inclusions, reduce trapped gas from liquid metal and provide laminar flow, and then the filtered metal significantly becomes cleaner. In this study, bentonite containing $\mathrm{Al}_{2} \mathrm{O}_{3}$ ceramic filters were developed rather than honeycomb ceramic filters so that laminar flow is obtained and velocity of molten $\mathrm{Al}$ can be controlled. Replica technique was used to make reticulated ceramic foam from the sponges. Bentonite was used to bind alumina particles both in room temperature and sintering temperature. Number of pores per inch and pore sizes were optimised for sufficient molten aluminium flow. Surface properties of the ceramic filters are also improved in order to control flow velocity.
\end{abstract}

DOI: 10.12693/APhysPolA.134.332

PACS/topics: ceramic filters, aluminium melt cleaning, aluminium casting, alumina foam

\section{Introduction}

Filtration is one of the most typical refining casting processes to eliminate the non-metallic and intermetallic inclusions during the aluminium alloy castings. The refining of melts results in increased homogeneity of the metal, improved mechanical properties, removal of many metallurgical defects, improvement of casting surfaces and significantly improved machinability [1-3]. The main sources of inclusions are slag-metal oxidation products, refractory materials, refining agent residua, mold materials and erosion, endogenous inclusions in metal and non-dissolved inoculant or alloying addition residua [3-5]. The filtration process is a complex mechanism influenced by hydrodynamic factors such as fluid flow, turbulence, surface and body forces, as well as chemical and metallurgical interactions among the inclusions, the filter media, and the liquid metal [4-6].

Reticulated ceramic foam filters have been used commercially in the foundry industry for last decades. Metal filtration using foam ceramic filter media has been found to be an effective means of controlling the level of inclusions [7]. The foam filter was recognised to have a unique, twisted canals through its body, which trapped inclusions and allowed clean, laminar melt flow to exit into the mould cavity [4-7]. Ceramic foam filters have open pores and windows structure with a very high volume of porosity and very high surface area to trap inclusions [6]. Ceramic foam filters work in a mode of deep bed filtration where inclusions smaller than the pore windows are retained throughout the cross-section of the filter. Inclusion capture in deep bed filtration is considered to be a result of two sequential events: transport of an inclusion

\footnotetext{
*e-mail: ademir@sakarya.edu.tr
}

to capture sites on the filter media and attachment of the particles to these site $[7,8]$. Ceramic foam filters are produced by penetrating reticulated polyurethane foam with a ceramic slurry, removing the excess slurry by squeezing the slurry impregnated sponge, then drying ceramic coating, firing the sponge and sintering the body [7-9]. Ceramic filter material must be able to withstand the initial melt stroke and thermal shock so that filter material does not spall or break down. Chemical inertness is also essential for the filter materials [7].

In this work, the wetting behaviour of aluminium, as a combination of surface and body forces, was investigated to improve the aluminium filtration.

\section{Materials and methods}

The Replica technique was used to fabricate high porous ceramic foam for liquid metal filtration using polyurethane sponges supplied from China as a shown in Fig. 1a. Alumina particles with different bentonite rates were mixed within pure water in agate mortar to prepare ceramic slurry. After adjusting viscosity and $\mathrm{pH}$ value the slurry was infiltrated to the reticulated polyurethane sponge by sequential squeezing the sponge within the slurry (Fig. 1b). The infiltrated body was then rolled up to squeeze out excess slurry. All polyurethane pore surfaces were daubed with ceramic mixture after drying (Fig. 1c). The slurry infiltrated samples were placed in a chamber furnace (Protherm PLF 130/9) and fired at $500^{\circ} \mathrm{C}$ for $30 \mathrm{~min}$ to burn out the polyurethane sponge. The remaining ceramic mixture was sintered at $1250^{\circ} \mathrm{C}$ to produce rigid and highly porous ceramic filter. The sintering provides strength increase of the ceramic foam which is beneficial for melt filtration. Optical micrograph was used to examine pore morphology and to illustrate molten metal filtration. The following figures show the as-received $10 \mathrm{ppi}$ sponge, schematic representation of slurry impregnation and impregnated and dried ceramic. 

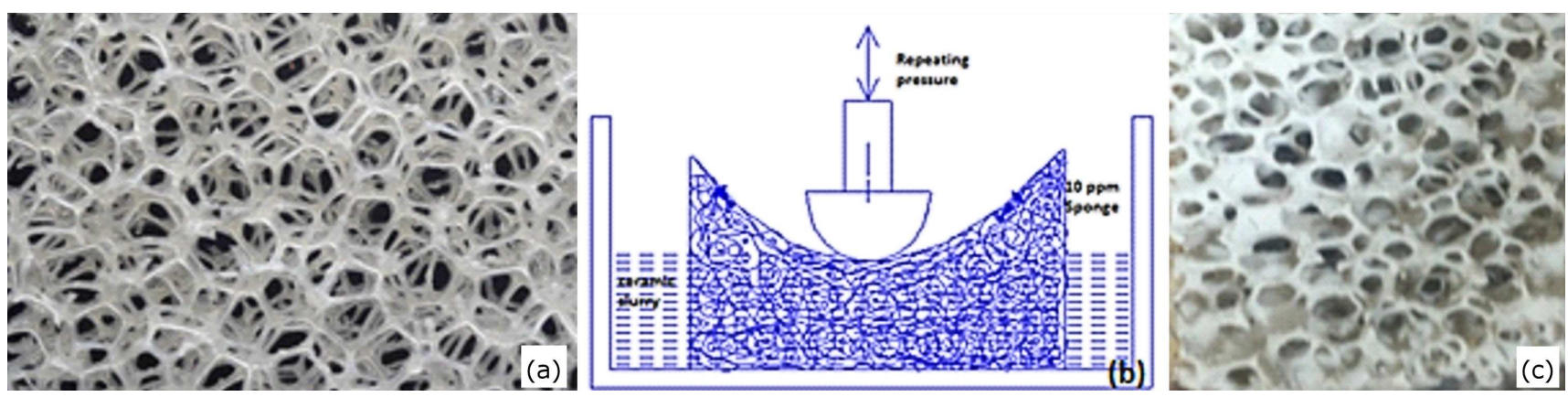

Fig. 1. Schematic representation of slurry impregnation: (a) 10 ppi polyurethane sponge, (b) slurry impregnation, (c) dried alumina impregnated sponge.

\section{Results and discussion}

Alumina powders were mixed with different rate of bentonite and water added to the powder mixture to prepare ceramic slurry. $45 \mathrm{wt} \%$ ceramic content of the slurry was the ideal rate for slurry infiltration ceramic. When ceramic impregnated sponge was dried, the bentonite bound alumina particles together at the sponge surfaces. Even, this bounding continued during polyurethane sponge burning. No ceramic damage was observed after the sponge burnt out. Thus, sponge morphology was exactly replicated to the green ceramic foam at $500{ }^{\circ} \mathrm{C}$ polyurethane burning and then weak $\mathrm{Al}_{2} \mathrm{O}_{3}$ ceramic foam is obtained. To strengthen the foams and convert to casting filters, the green foams were sintered at $1250{ }^{\circ} \mathrm{C}$ for $60 \mathrm{~min}$. Finally highly porous aluminum casting filters were obtained. Surprisingly, no shrinkage was observed and homogeneous porosity and reticulation were obtained as shown in Fig. 2a,b. The pores were interconnected with windows which was necessary for inclusion filtration.

X-ray diffraction (XRD) analysis was also carried out to determine occurring phases after sintering. As shown in Fig. 3, only corundum alumina was detected. Although $16 \mathrm{wt} \%$ bentonite was used, no related phase with the bentonite was observed from the XRD pattern. Most probably alumina within the bentonite reacted with alumina particles and trace amount of silicate left as a different phase. However this amount was not sufficient to detect during the XRD analysis.

Different pore sizes of the fabricated filters were used for Al-Si alloy casting to determine which size is efficient for flow control. Laminar flow is essential for the melt within gate system. Gate system is supposed to be full during pouring, otherwise air is trapped and occurrence of oxide film is increased. By means of ceramic filter, the flow speed was slowed within the runner and instant backfill was observed within the sprue. Backfill means that the melt flow is slowed by the fabricated filters and flow speed reduced the standard value. Extreme speed can cause turbulence and folded oxide film which is harmful for mechanical properties especially for tensile strength and fracture toughness. Thus there is a balance between backfill in the spreu and the melt flow speed
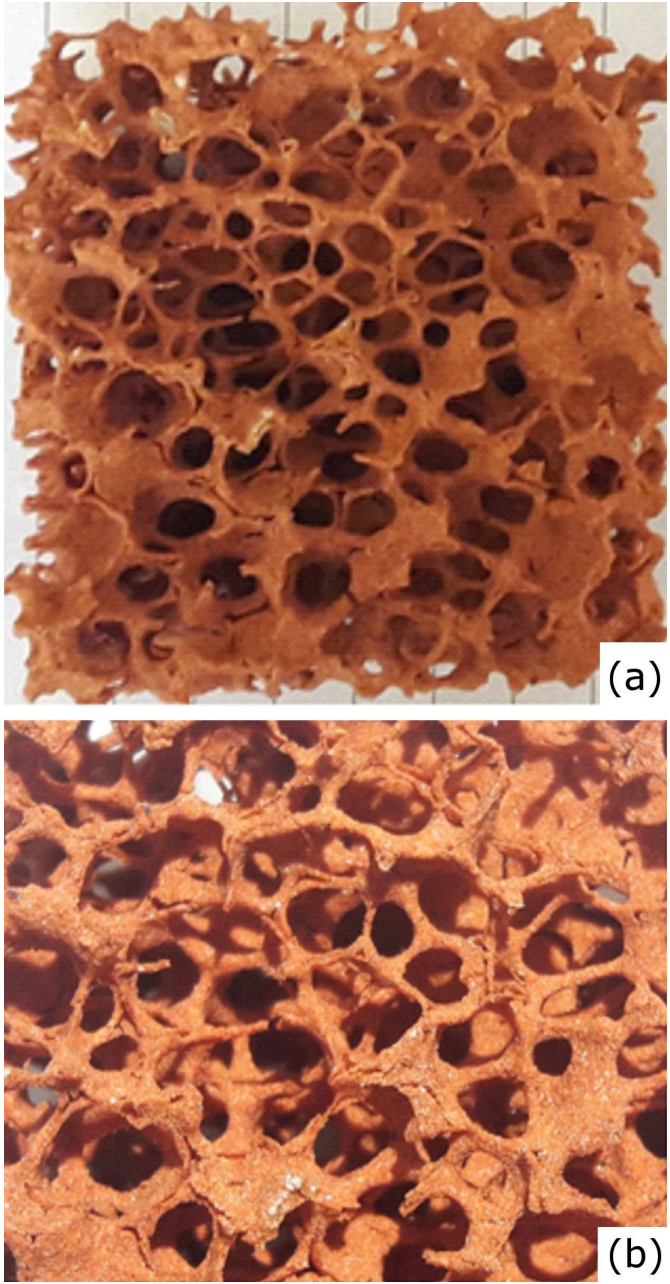

Fig. 2. Alumina ceramic filter (a) shows homogeneous pore distribution, (b) shows reticulated ceramic foam.

in the runner. The filter does not only clarify the melt but also hinders the melt flow. As the pore size was decreased, the backfill rate increased and melt flow was retarded. The filter produced 30 and 45 ppi sponges which did not show sufficient melt flow and therefore over backfill took place. 20 and 10 ppi reticulated filter was successful for $\mathrm{Al}$ alloy filtering and flow arrangement. Best 


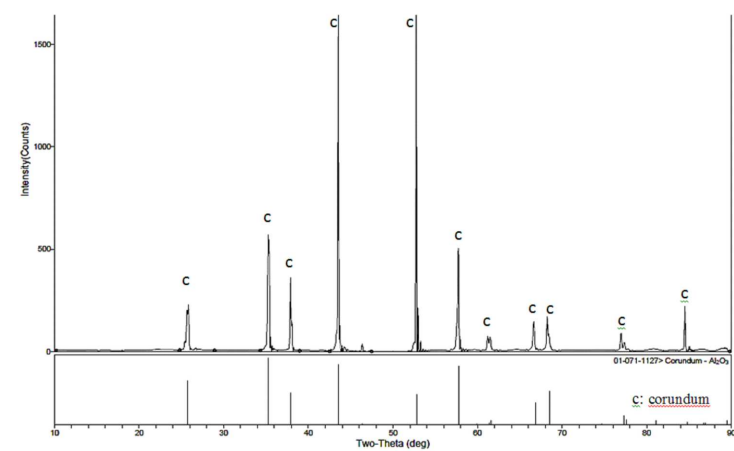

Fig. 3. XRD pattern of the produced ceramic filter.

laminar flow and melt purification from the inclusion and slags were achieved with the 10 ppi alumina ceramic filter as shown in Figs. 2-4. Figure 5a shows that slag particles was captured. It means that $\mathrm{Al}$ melt filtering is successful as well.
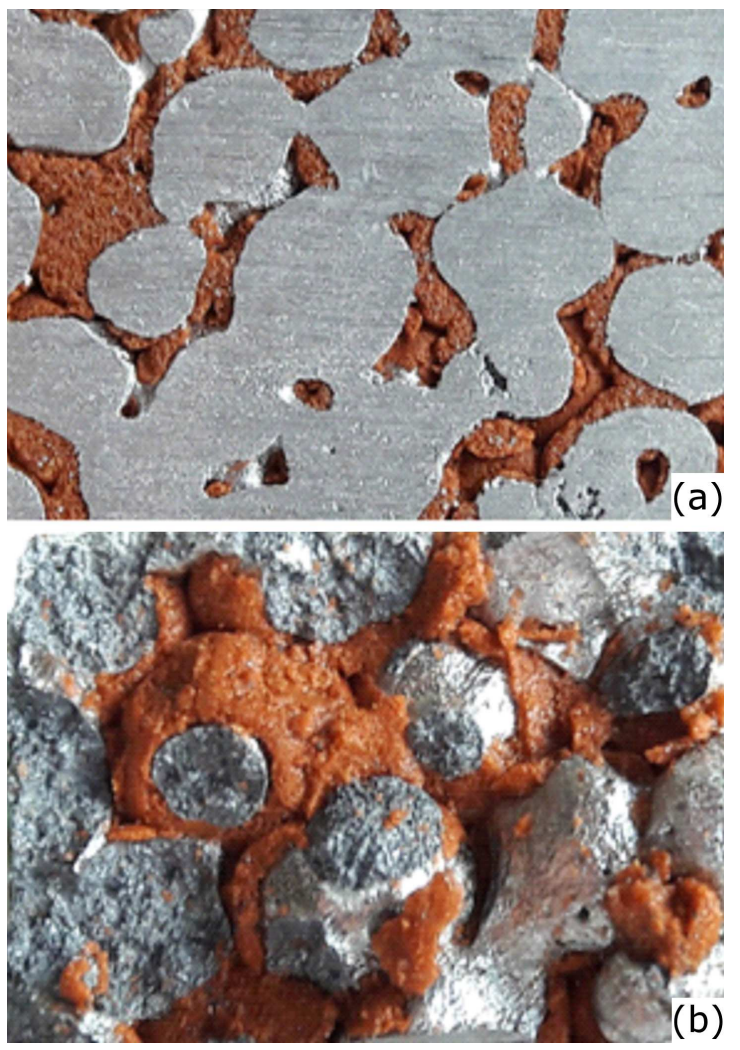

Fig. 4. Filtering molten $\mathrm{Al}$ after gas and slug elimination: (a) cross-section of the cast filter, (b) crack surface of the cast filter.

\section{Conclusion}

The ceramic content of slurry and $\mathrm{pH}$ value were adjusted to achieve a successful slurry infiltration. Different kind of sponge tested and found that 10 ppi sponge morphology was convenient to produce alumina ceramic filters and aluminum melt filtration. $1250^{\circ} \mathrm{C}$ open air sintering is sufficient to reach desired phase and strength.
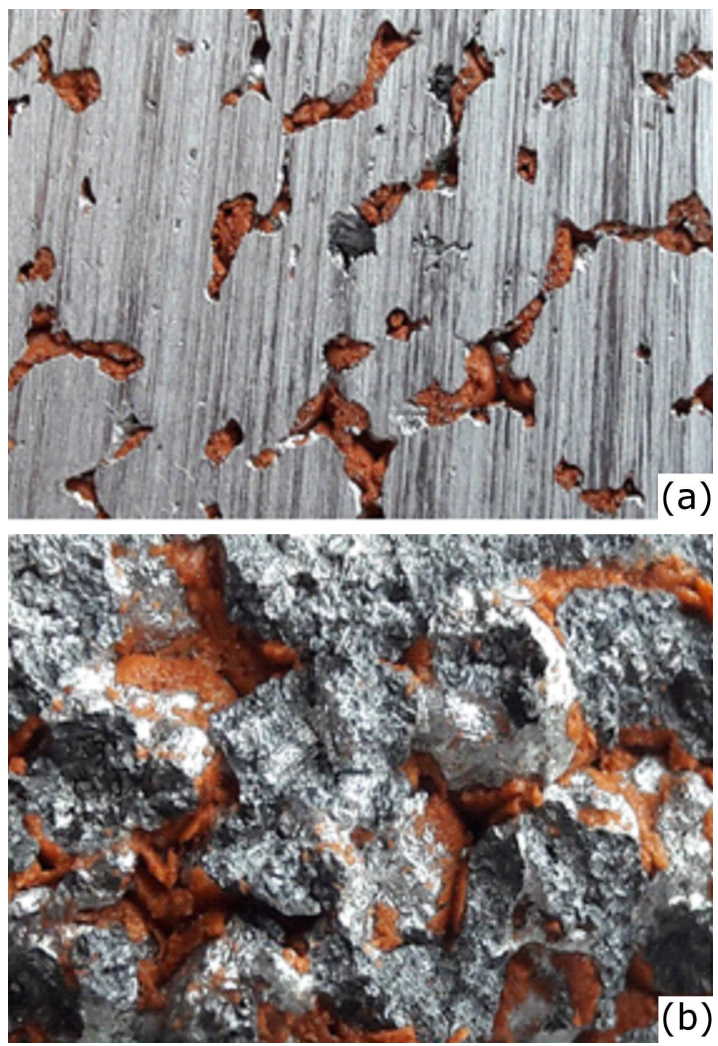

Fig. 5. No purification is applied before $\mathrm{Al}$ casting: (a) cross-section of the cast filter, (b) crack surface of the cast filter.

Casting tests showed that the resulting ceramic filters were successful for aluminum melt filtration. The produced ceramic filters can also be used for flow control in runner so that melt can flow with no turbulence and folded oxide film. This study comes to a conclusion that these casting filters are especially suitable for $\mathrm{Al}$ melt filtration. Hence, the produced alumina ceramic foam filters can be used in aluminum casting industry as casting filters.

\section{References}

[1] S. Bao, M. Syvertsen, A. Kvithyld, T. Engh, Trans. Nonferr. Met. Soc. China 24, 3922 (2014).

[2] F. Chen, X. Huang, Y. Wang, Y. Zhang, Z. Hu, Mater. Lett. 34, 372 (1998).

[3] Z. Taslicukur, C. Balaban, N. Kuskonmaz, J. Europ. Ceram. Soc. 27, 637 (2007).

[4] D. Kacaefe, A. Murray-Chiasson, Y. Kocaefe, P. Waite, Metall. Mater. Trans. B 35, 999 (2004).

[5] L. Liu, F.H. Samuel, J. Mater. Sci. 32, 5907 (1997).

[6] M. Syvertsen, S. Bao, Metall. Mater. Trans. B 46 , 1058 (2015).

[7] X. Liang, Y. Li, J. Liu, S. Sang, Y. Chen, B. Li, C.G. Aneziris, Ceram. Int. 42, 13091 (2016).

[8] L. Jian-Guo, Ceram. Int. 20, 391 (1994).

[9] V. Laurent, D. Chatain, N. Eustathopoulos, J. Mater. Sci. 22, 244 (1987). 